\title{
El Catauro de cubanismos de Fernando Ortiz y la reinvención de tradiciones filológicas
}

\author{
Graciela SALTO \\ Universidad Nacional de La Pampa, CONICET \\ gsalto@hotmail.com
}

\begin{abstract}
RESUMEN
El legado lexicográfico del antropólogo cubano Fernando Ortiz adquirió renovado valor en las últimas décadas. Gustavo Pérez Firmat, entre otros críticos literarios y culturales, encontraron en ese acervo los fundamentos de configuraciones simbólicas más amplias y heterogéneas que las sostenidas durante el auge cultural del período revolucionario. En este artículo se revisan someramente los textos lexicográficos que fueron reconsiderados en las últimas décadas; se señalan algunos hitos de la recepción de esa producción lingüística y se analizan sus consecuencias sobre el proceso de reinvención de tradiciones filológicas en la literatura cubana actual.
\end{abstract}

Palabras clave: tradición literaria, filología, Gustavo Pérez Firmat, Fernando Ortiz, literatura cubana.

\section{The Cautaro de cubanismos of Fernando Ortiz and the reinvention of philological traditions}

\begin{abstract}
The lexicographical legacy of the Cuban anthropologist Fernando Ortiz renewed their value in recent decades. Gustavo Pérez Firmat, among other literary and cultural critics, found in this collection the background of broader and heterogeneous symbolic configurations than those held during the cultural boom of the revolutionary period. The purpose of this paper is to briefly review the lexicographical texts that were reconsidered in recent decades; point out some milestones of the reception of such linguistic production and analyze its impact on the process of reinventing philological traditions in contemporary Cuban literature.
\end{abstract}

Key words: literary tradition, philology, Gustavo Pérez Firmat, Fernando Ortiz, Cuban literature.

Sumario: 1. Léxicos, glosarios y etimologías. 2. De la lexicografía a la literatura: las lecturas afiliativas. 3. Giros filológicos.

Los apuntes lexicográficos del antropólogo cubano Fernando Ortiz (1881-1969) cobraron una inusitada actualidad en las últimas décadas y aparecieron en medio de 
controversias impensadas en el momento de su publicación. Más allá del reconocimiento del valor historiográfico de sus investigaciones lingüísticas ${ }^{1}$, algunos de sus estudios sobre el léxico fueron leídos también como ficciones modernas equiparables a Ulysses de James Joyce o The Waste Land de T. E. Eliot (Pérez Firmat $1986^{2}$ ). Esta comparación anticipó, en pocos años, los cambios culturales que siguieron al derrumbe soviético e hizo visibles algunos de los cambios por venir en la articulación de tradiciones filológicas ${ }^{3}$. Así, un corpus de diccionarios que, desde las primeras décadas del siglo XX, había integrado los archivos de la lingüística y de la antropología amplió su dominio discursivo y, casi una centuria después, ingresó de lleno en las discusiones sobre la modernidad y sobre la impronta vanguardista de la nueva etapa cultural. Este ingreso se produjo, en gran medida, por dispositivos de lectura originados en la diáspora, que incidieron sobre los modos de leer y de comprender la obra general de Fernando Ortiz. En este artículo se revisan someramente los textos lexicográficos que fueron reconsiderados en las últimas décadas por la crítica literaria; se señalan algunos hitos de la recepción sesgada de esta producción lingüística y se analizan sus consecuencias sobre el proceso de reinvención de tradiciones filológicas en la literatura cubana actual.

\section{Léxicos, glosarios y etimologías}

La lexicografía del continente tiene uno de sus núcleos fundacionales en Cuba, puesto que el primer diccionario diferencial del español en América fue el del geógrafo Esteban Pichardo y Tapia. Las cuatro ediciones de su Diccionario provincial de voces cubanas - 1836, 1849, 1861-1862 y 1875- demuestran la difusión y el impacto de esta precursora colección de americanismos. En los años siguientes, se publicaron también otros léxicos similares en la isla ${ }^{4}$, en consonancia con un movimiento general de afirmación de las diferencias en el habla y la

1 Algunas apreciaciones sobre este legado pueden consultarse en Camacho Barreiro (2000), Font y Quiroz (2005) y Valdés Bernal (2006).

2 Cfr. "Ortiz's dictionary is one of our most typical and finest modern texts, a philological fiction comparable to Ulysses or The Wasted Land" (Pérez Firmat 1986: 108).

${ }^{3}$ Sobre los cambios producidos en la crítica de la cultura cubana de ese período, véase Sklodowska (2010).

4 De 1795 data el primer intento conocido: "Memoria que promueve la edición de un Diccionario provincial de la Isla de Cuba". En 1859, se publicó el Índice Alfabético y Vocabulario Cubano de José García de Arboleya; en 1885, el Diccionario cubano, etimológico, razonado y comprensivo de las voces y locuciones del lenguaje común y el de las dicciones del nomenclatur geográfico de José Miguel Macías; en 1886, Cuba primitiva, origen, lenguas, tradiciones e historia de los indios de las Antillas Mayores y las Lucayas de Antonio Bachiller y Morales; en 1914, Lexicografía antillana, de Alfredo Zayas; entre los más conocidos (Camacho Barreiro 2000-2004: 21-23; 27-29). 
escritura locales frente a las presiones de las Academias de la Lengua por imponer una variedad monolingüe (Guitarte 1991; Córdoba Rodríguez 1999). En 1915 apareció, por ejemplo, El habla popular a través de la literatura cubana. Estudio sobre su transformación de Juan Miguel Dihigo Mestre, filólogo de la Universidad de La Habana a quien Fernando Ortiz dedica, pocos años después, la primera versión de su Catauro de cubanismos (1923).

Este interés por los estudios léxicos es un proceso de larga duración que se potencia en Cuba, entre 1920 y 1930, a partir del cuestionamiento del racialismo positivista que había dominado la conceptualización de las culturas africanas y nativas en las décadas precedentes. La heterogeneidad étnica y cultural que conformaba la población de la isla se había hecho cada vez más notoria tras la guerra de 1898 y fue, en las décadas siguientes, cuando varios intelectuales se concentraron en la identificación, el registro y la catalogación de prácticas y usos culturales que, a tono con las teorías vigentes, se consideraron idiosincráticos de la identidad cubana (Naranjo Orovio 2003; Ortiz García 2003; Mailhe 2011). En este proceso se organizaron e institucionalizaron los estudios folklóricos y se dio renovado impulso a la investigación de las variedades locales de la lengua. De esta época data el Vocabulario cubano de Constantino Suárez, "El Españolito", publicado en La Habana y en Madrid al mismo tiempo. Este repertorio apareció como suplemento a la decimocuarta edición del diccionario de la Real Academia de la Lengua publicada en 1921 y obtuvo cuestionamientos inmediatos.

A los pocos meses, Fernando Ortiz comenzó a publicar unas "papeletas" léxicas en la Revista Bimestre Cubana e, incluso, en el número de enero-febrero de 1921, apareció una extensa reseña crítica sobre el trabajo de Suárez ${ }^{5}$. En el año 1923, la reprodujo como prólogo a su propio léxico: el Catauro de cubanismos, y como epílogo agregó unas consideraciones para terminar el "vocabulario cubano de Suárez" (Ortiz 1923: 248). Si bien rescata que el repertorio de su antecesor tenía el valor de haber incorporado "las palabras indecentes, y basarse con frecuencia en el léxico del vulgo", le reprocha no haber profundizado en las diferencias "del hampa afrocubana" (255) y, de haber seguido, en cambio, con demasiada pulcritud las orientaciones de la Real Academia. La visión de Ortiz era, por entonces, mucho más abierta, flexible y cosmopolita que la de sus contemporáneos (Mailhe 2011; Birkenmaier 2012). Postulaba la necesidad de "un plan integral hispanoamericano", que debía superar la mera "tarea de acopio" de localismos o regionalismos y abarcar, en cambio, el registro de la heterogeneidad propia del mundo americano:

5 Véase Fernando Ortiz, "Un catauro de cubanismos", Revista Bimestre Cubana 16 (mayo-junio 1921): 129-157. 
Afortunadamente, los iberoamericanos tenemos tradición filológica que no desmerece en nada de la española y no pocos autorizados maestros. Recordemos a Bello, Pacheco, Cuervo, Selva, Lenz, Letellier, Gagini, Rivodó, Garzón, Segovia, Tovar, Uribe, Monner, Ramos Duarte, Palma, Membreño, Icazbalceta, Granada, Calcaño, Coll y Toste, Ureña y tantos otros" (Ortiz 1923: 14).

En la línea de esta tradición filológica americana, Ortiz ofrece su "cataurito" (1923: vii), en irónico diminutivo ${ }^{6}$. Es un repertorio que completa, corrige y enmienda las omisiones africanistas del vocabulario académico, "un mamotreto de 'cubicherías' lexicográficas, un pobre catauro colmado de frutos del país" (1923: 15). Este catauro, que había aparecido por entregas en la Revista Bimestre Cubana, no alcanzó formato de libro hasta 1923, cuando se publica en La Habana con el subtítulo Apuntes lexicográficos. Fue una obra muy leída y consultada, aunque la opacó, en cierta medida, la aparición inmediata del más específico y extenso Glosario de afronegrismos, en 19247. En las últimas décadas, en cambio, se potenció su valor estratégico para la configuración de una lexicografía atenta a las diferencias propias del multilingüismo y a la diversidad étnica y cultural.

Stephen Fay (2010) destacó, por ejemplo, la capacidad operativa de las "cubicherías lexicográficas" del Catauro en la configuración de un pensamiento moderno sobre la identidad cubana. Este proceso habría alcanzado un punto de inflexión en el año 1923, la fecha de publicación del diccionario de Ortiz, ya que, por entonces, se hizo visible un desplazamiento conceptual desde una identidad anclada en lo telúrico hacia una matriz mucho más fluida y móvil. Las búsquedas etimológicas de Ortiz coincidirían con este movimiento ${ }^{8}$, en el cual sobresale la catalogación de los usos criollos de la lengua frente a los parámetros hispanizantes que caracterizan la mayoría de los léxicos de la época. Fay recupera un ejemplo del Catauro, citado por Gustavo Pérez Firmat (Fay 2010: 44). En la entrada correspondiente al término "guayabo", Fernando Ortiz discute la referencia francesa que aparece en el Diccionario de la Academia y llega a decir: "esa etimología si se propone como tal [la francesa], no vale una guayaba, para decirlo en criollo" (1923:

${ }^{6}$ Nótese que la versión impresa está integrada por doscientas setenta páginas.

${ }^{7}$ En la correspondencia de Ortiz compilada y anotada en 2014 por Trinidad Pérez Valdés puede observarse que el envío y la recepción del Catauro coinciden, en general, con los del Glosario de afronegrismos. Véase, por ejemplo, el intercambio epistolar con Rodolfo Lenz (Ortiz 2014: 33-35).

${ }^{8}$ Fay señala la coincidencia en 1923, "annus mirabilis" en Cuba, de varios movimientos que buscan cierta independencia ideológica: la creación de la Federación Estudiantil Universitaria, liderada por Juan Antonio Mella, el movimiento de autonomía en la Universidad de La Habana y la formación de la Junta Cubana de Renovación Nacional, entre otros (2010: 46-48). 
43; en itálica en el original $)^{9}$. El ejemplo ilustra las estrategias operativas del antropólogo cubano a favor de los usos populares y étnicos de la lengua en detrimento de las fuentes que, desde la primera edición del célebre Diccionario de Autoridades (1726-1739), proveían de referencias clásicas a los repertorios académicos Decirlo "en criollo" es, en ésta y en otras entradas, mucho más relevante que una cita de autoridad. De este modo, el vocabulario de Ortiz abre la posibilidad de cuestionar el estatuto monolingüe de los léxicos usuales y ofrece un modelo para la representación de las múltiples voces que integran la cubanía, una condición que, como explicará varias décadas más tarde (Ortiz 1964), no sería patrimonio exclusivo de quienes viven en la isla, sino la sumatoria de los rasgos discursivos de quienes se reconocen en una misma comunidad cultural, más allá de los lugares y de los territorios por donde transiten (Fay 2010: 48) ${ }^{10}$.

En un artículo publicado también en 2010, Stephan Palmié analiza, en el mismo Catauro, cómo la búsqueda de étimos africanos contrasta con las políticas etimológicas de la época. El procedimiento más visible en este repertorio sería la negación o la subversión de las referencias que, en el Diccionario de la Real Academia de la Lengua, vinculaban los usos cubanos con los españoles. En su lugar, Ortiz postula una autonomía idiomática basada en antecedentes africanos o indígenas mediante un procedimiento comparativo propio de la filología de los siglos anteriores. Establece relaciones homofónicas entre vocablos africanos antiguos y voces usadas en la actualidad en Cuba y los compara, sin llegar a identificar cómo podría haberse producido la derivación etnolingüística del lexema. Solo busca localizar los orígenes de la población africana de donde habría provenido la referencia (Palmié 2010: 41). Algunos de los pasos de este procedimiento pueden advertirse en el ejemplo siguiente:

Brujo, ja. adj.—Que practica la brujería. Que es propio de la brujería.

Con las voces bruja y brujo el léxico académico no ha sido del todo cuidadoso.

En el artículo BRUJA entiende este vocablo como adjetivo, en todas sus acepciones, inclusive en la tercera: 'Mujer que, según la opinión vulgar (y a veces según la docta eclesiástica, pudiera añadirse), tiene pacto con el diablo, y hace cosas extraordinarias por su medio'. Esta acepción parece la definición de un sustantivo; si se quiere, de un adjetivo sustantivado. Creemos que o BRUJA es,

${ }^{9}$ Cfr. "Guayabo.- El árbol que produce la guayaba, dice el Diccionario de la Academia. ¿Pero por qué añade: 'En francés goyavier'? ¿Quiere decir con esto que es un galicismo? ¿Sí? Pues no es verdad; como no lo es guayaba, tampoco lo es guayabo. ¿No? ¿Pues qué, acaso en cada otra papeleta del Diccionario se trae a colación la traducción francesa de cada vocablo? ¡Fuera, pues, el goyavier! Esa etimología, si se propone como tal, no vale una guayaba, para decirlo en criollo [...]" (Ortiz 1923: 43; en itálica en el original).

${ }^{10}$ El valioso estudio de Stephen Fay analiza, en extenso, las configuraciones metafóricas que fundamentan estas hipótesis. 
además de adjetivo, sustantivo, como lo es, según el propio diccionario, la voz BRUJO; o no lo es tampoco este último vocablo. Si ambos son sustantivos, la Academia ha debido indicarlo, señalando al frente de esa acepción tercera la inicial efe, del género femenino. O redactar un artículo más, que sería más apropiado. (Ortiz 1923: 268)

La cita exhibe, sin eufemismos, las disonancias entre dos posturas lexicográficas poco conciliables. Por un lado, se describen las acepciones ortodoxas del diccionario académico. Por otro, se pone de manifiesto un distanciamiento irónico, casi satírico, que impugna sus procedimientos a la par que denuncia, incluso, su adecuación a los requerimientos de la doctrina eclesiástica. Este cuestionamiento se expande también a los repertorios publicados en la isla con anterioridad -el de Pichardo y Tapia, en primer lugar; el de Constantino Suárez, en fecha más reciente- ya que, según Ortiz, también contienen errores ${ }^{11}$. El principal sería no haber tomado en cuenta las etimologías de origen africano:

Al 'tasajo malo' se le llamó BRUJO, porque los lucumíes lo dijeron buruh 'malo', y buruju 'peor'. (Crowther, 99. $)^{12}$ Y sabido es que el tasajo brujo fue en Cuba la base de la alimentación del esclavo.

La acepción cubana, o afrocubana, pues, debemos recogerla así: 'Dícese del tasajo de mala calidad'. (Ortiz 1923: 268).

Se llega así a una definición etimológica a partir de rasgos homofónicos: "brujo /a" sería de origen lucumí, porque los esclavos decían que el tasajo era: buruh o buruju. El resultado de este procedimiento es, en la mayoría de los casos, una inversión, irónica y paródica, de las etimologías registradas en los diccionarios anteriores, a partir de una disquisición que excede el campo de la lexicografía. El "tasajo brujo", una comida popular en la isla, se transforma, en esta versión, en una denuncia sobre la mala alimentación de los esclavos. Según el Catauro, "Brujo" no querría decir "aditamento" al tasajo, sino - como aparece en los repertorios anteriores - "comida en mal estado" que servía de alimento a los esclavos. Es decir, la explicación meramente etimológica de los diccionarios anteriores obtura la denuncia política implícita en el étimo africano. "Brujo" es tasajo malo, en mal

${ }^{11}$ Cfr. "En Cuba tiene otra acepción el adjetivo [BRUJO], aplicado exclusivamente al tasajo. [Constantino] Suárez dice: 'Sirve de aditamento al tasajo, boniato, etc.'; pero no especifica su sentido en ese caso, ni la razón del mismo. [Esteban] Pichardo decía: 'TASAJO. Por antonomasia se entiende el que viene de ultramar [...] La opinión folklórica, recogida por Pichardo, es inexacta, nacida del deseo popular de hallar una explicación al adjetivo BRUJO, aplicado a ese tasajo" (Ortiz 1923: 268).

${ }^{12}$ Referencia a la recopilación de Samuel Ajayi Crowther (1807-1891), A Vocabulary of the Yoruba Language (Londres: Seeleys, 1852). 
estado, y esta definición etimológica tiene un componente político insoslayable. Esta sería la razón fundamental de la enmienda que propone Ortiz: la lexicografía hispana habría contribuido a invisibilizar la esclavitud mediante el ocultamiento de las raíces etimológicas africanas. En su visión, ha llegado el momento de reponer esos étimos en el diccionario y a revertir una lexicográfica anquilosada. De hecho, al año siguiente, en 1924, publicó su Glosario de afronegrismos, donde amplía y complejiza este procedimiento $\mathrm{y}$, por la misma época, participa también activamente en la formación de la Academia Cubana de la Lengua, fundada en $1926^{13}$.

Entre este año y 1928, la revista Archivos del Folklore Cubano, dirigida por el mismo Ortiz ${ }^{14}$, publicó otra contribución lexicográfica que dialogó tanto con el Vocabulario de Constantino Suárez como con el Catauro: Un guacalito de cubanismos de Juan Marinello Vidaurreta (1898-1977). Este léxico, reproducido en 1999 por la revista Oralidad $^{15}$, se presenta como una "fe de erratas modestísima" que intenta corregir y completar los repositorios anteriores; en especial, "purgar el actual Catauro de errores nacidos de la dificultad en que ha estado su autor de acercarse y permanecer entre nuestros campesinos y gente maleante y de observar muy de cerca, el uso de muchas expresiones locales" (Marinello 1926: 109) ${ }^{16}$. Este reclamo por una mayor cercanía a las clases populares y al ambiente rural no parece ser un escollo para el reconocimiento del trabajo lexicográfico de su antecesor, ya por entonces un prestigioso folklorista, sino un intento de profundizar las opciones léxicas desplegadas por Ortiz. De hecho, los dos repertorios comparten títulos similares: catauro y guacalito son recipientes o cestos de uso común en el área cubana para recolectar y transportar todo tipo de productos entremezclados ${ }^{17}$. Son

${ }^{13}$ Sobre la participación de Fernando Ortiz en el proceso de creación y consolidación de la Academia Cubana de la Lengua, véase el estudio de Motola Pedroso (2014).

${ }^{14}$ Fernando Ortiz figura como director a partir del volumen 2 (1926). El equipo editorial se completa con Emilio Roig de Leuchsenring, Joaquín Llaverías, Manuel Pérez Beato, Francisco G. del Valle y Carolina Poncet. Para un análisis de la revista y de sus vínculos con la Sociedad del Folklore cubano, véase Ortiz García (2003).

${ }^{15}$ La primera parte se publicó en Archivos del Folklore Cubano, vol. II, no 2 (mayo de 1926), pp. 108-119; la segunda y tercera secciones aparecieron en el vol. II, $\mathrm{n}^{\mathrm{o}} 3$ (octubre de 1926), pp. 228-235 y pp. 363-368, respectivamente; la cuarta y última parte, en el vol. III, $\mathrm{n}^{\mathrm{o}}$ 1 (enero-marzo de 1928), pp. 21-26. La edición solo llega hasta la letra "P" del alfabeto.

16 Sobre el tipo de enmiendas propuestas al Catauro, véase el ejemplo siguiente: “Aguajirarse: Ortiz dice: 'como guajiro, apocado, tímido'. Sí, pero además, vestirse a lo rústico”. (Marinello 1926: 110).

${ }^{17}$ La nota “¿Por qué catauro?”, incorporada en el primer número de la revista del mismo nombre, explica la definición usual: "En Cuba se utiliza el vocablo 'catauro' para denominar un tipo de cesto hecho de fibras de yaguas tejidas, que sirve para transportar frutas, carnes y otros artículos, principalmente en las zonas rurales. Esteban Pichardo es quien documenta 
objetos de la vida cotidiana que irrumpen en el dominio de la lexicografía y su sola imagen contribuye a la corrosión de la jerarquía y legitimidad de los diccionarios y vocabularios académicos. Por esta actitud corrosiva y moderna, fueron reconocidos varias décadas después, en especial, el Catauro.

\section{De la lexicografía a la literatura: las lecturas afiliativas}

La espontaneidad y la irreverencia del Catauro nunca dejaron de llamar la atención. Poco antes de morir Fernando Ortiz, en 1969, un veintiañero Reynaldo González le preguntó por las razones del aparente desorden del libro:

En los primeros años sesenta [....] conocí al sabio cubano en la casa de El Vedado que ahora ocupa la fundación que lleva su nombre [...]. Ortiz me obsequió su libro Catauro de cubanismos en su primera edición (1923), un ejemplar rescatado de alguna librería de uso y ya dedicado a otra persona.

Tachó la dedicatoria y puso algunas palabras para el recién llegado a su casa [...] Mientras transcurría la conversación sobre temas de la cultura cubana, eché una ojeada al libro, un tomo breve, forrado con el recurrente papel amarillo de las notarías y las escuelas públicas. Me sorprendió el desorden en que estaban los vocablos $[\ldots]$

- Caramba, Don Fernando — le dije - , es el primer diccionario que veo sin orden alfabético.

— ¿Usted sabe lo que es un catauro? — respondió.

En su entonación recibí como un regaño a un joven de ciudad que desconocía las cosas del campo.

—Por supuesto — salté, alerta—, sé lo que es un catauro. En mi casa teníamos catauritos para ajíes, ajos y cebollas. Los vendedores ambulantes llegaban a la puerta con catauros de frutas.

- Pues sabrá que en un catauro lleno, las cosas se revuelven. No hay orden alfabético en un catauro - cerró el tema con una sonrisa amable.

En el recuerdo de Reynaldo González (2002), Ortiz habría reafirmado, cuarenta años después de la publicación original de su "Mamotreto de 'cubicherías' lexicográficas" (Ortiz 1923: 17), la validez estratégica del desorden alfabético de su repertorio. Este desorden estaba en consonancia con los usos populares y criollos de la lengua: mezclaba, confundía, desjerarquizaba, impregnaba unos y otros, modernizaba. Es necesario admitir, no obstante, que el orden alfabético estuvo previsto en algún momento del proceso de publicación original del Catauro, ya que

por primera vez esta voz como de uso en el español de Cuba" (Catauro 1999: 114). De modo similar, el vocablo guacal se define, en el actual Diccionario de la Real Academia Española, como "especie de cesta o jaula formada de varillas de madera, que se utiliza para el transporte de loza, cristal, frutas, etc.", con uso extendido en Canarias, Colombia, Cuba, Ecuador, México, República Dominicana y Venezuela. 
Ortiz adelanta en la advertencia al lector y en la conclusión que habrá una edición posterior ordenada con mayor cuidado ${ }^{18}$. No llegó a hacerlo y es posible conjeturar que haya advertido el potencial ideológico de su mezcla desordenada de "cubicherías", ya que sus trabajos posteriores avanzaron en una línea de pensamiento cada vez más vinculada con las matrices de la transculturación cultural ${ }^{19}$.

Sin embargo, el orden con que la revolución pretendió organizar los símbolos culturales de los nuevos tiempos habría llegado, incluso, hasta el Catauro y pocos años después de su muerte, la Editorial de Ciencias Sociales de La Habana publica un Nuevo Catauro de cubanismos (1974) que ordena alfabéticamente las voces del original, además de incorporar otras nuevas. La justificación es que la versión de Ortiz: "adolece del defecto de no tener el léxico ordenado alfabéticamente." (Catauro 1999: 115). Con el objetivo de resolver esta carencia, el Nuevo Catauro ordena, cataloga y jerarquiza aquello que Ortiz había preferido mezclar, con lucidez, para hacer visible la riqueza y la heterogeneidad de los usos populares de las lenguas, una mezcla que escapaba a las posibilidades taxonómicas del positivismo de los años veinte y coincidía, en cambio, con las búsquedas vanguardistas de su tiempo (Unruh 1994: 229).

Para entonces, ya hacía al menos diez años, que el Catauro había resurgido con significados muy disímiles entre los cubanos que vivían en la diáspora. En 1986, Gustavo Pérez Firmat (1949-), un cubano que reside en Estados Unidos desde que tenía once años de edad, le dedicó a este repertorio uno de los capítulos de Literature and Liminality. Festive Readings in the Hispanic Tradition. Es un libro escrito en inglés y dedicado, como la mayoría de las obras del autor, al problema de vivir y de escribir en los márgenes, en los umbrales, en las fronteras de la lengua, en el exilio, en el limen ${ }^{20}$. La "liminalidad", según entiende Pérez Firmat, no es tanto

${ }^{18}$ Cfr. estas dos citas en el Catauro de cubanismos: "Sin aderezo alguno, como simples apuntaciones de un mamotreto lexicográfico [...] así de publican hoy, para los lexicófilos que no desean esperar la tirada definitiva que de tales apuntaciones habrá de hacerse, después de ordenarlas alfabéticamente, corregirlas y adicionarlas con sendas observaciones" (1923: vii). En las páginas finales, véase: “verá probablemente la luz de la publicidad cuando florezcan los aguinaldos, una edición del catauro, con las papeletas por orden alfabético" (1923: 253).

${ }^{19}$ Ese "apelativo despectivo, y no sólo festivamente, como dice Suárez, que nos damos los cubanos [...] a un acto informal y poco serio le decimos cubichería" (Catauro 1923: 247).

${ }^{20}$ Entre algunas de las obras de Gustavo Pérez Firmat que abordan esta temática, véanse: Life on the hyphen. The cuban-american way (1994), un ensayo en el que investiga la condición bicultural del emigrado cubano en los Estados Unidos; El año que viene estamos en Cuba (1997), autobiografía escrita originalmente en inglés y luego traducida por el autor al español; My Own Private Cuba: Essays on Cuban Literature and Culture (1999); 
un concepto como un arquetipo conceptual que permite múltiples asociaciones: "etymologically, limen connects with nouns like limit, limb, limbo, limbus, slime, lintel; with verbs like limn, delimit, and eliminate; and with adjectives like preliminary, sublime, and subliminal" (XIV-XV). Para explicar este arquetipo, apela al antiguo Catauro de cubanismos, porque cree encontrar allí uno de los antecedentes más altos de la modernidad cultural. De las tres partes del libro, la segunda, "Choteo", incluye un apartado, "The Devil's Dictionary", dedicado al repertorio publicado por Ortiz en 1923. Con pocas variantes, este y otros textos sobre el antropólogo aparecen, también, en diversos ensayos del autor. En 1989, incluye el mismo capítulo en The Cuban Condition: Translation and Identity in Modern Cuban Literature y, diez años más tarde, varios estudios sobre la obra de Ortiz integran el volumen My Own Private Cuba: Essays on Cuban Literature and Culture (1999) ${ }^{21}$.

Este interés persistente en la obra del antropólogo se explica, en gran medida, por la apertura conceptual e ideológica que puede advertirse en el repertorio lexicográfico y en la consecuente modernidad del Catauro. Pérez Firmat identifica, en esta obra, tres estrategias disruptoras de los procedimientos de la lexicografía tradicional que potenciarían la liminalidad del repertorio. En primer término, señala el desarraigo de la fuente española de los vocablos mediante la propuesta de una etimología de origen no hispano, en general, aborigen o africano. El ejemplo más notorio sería el caso de "choteo", una entrada en la que se discute la referencia "choto" y se propone, en su lugar, una etimología lucumí o yoruba (1985: 89-99) ${ }^{22}$. En segundo término, advierte la propuesta de aceptación en el Diccionario de la Real Academia de palabras usuales en Cuba que no tenían correlato en el ámbito peninsular, como "garapiña", "mojiganga", "pucha", entre otras. De haberse aceptado esa propuesta, se habría invertido el flujo tradicional de étimos desde Europa hacia América, ya que el centro de irradiación de las raíces etimológicas se habría ubicado esta vez n el continente americano (1985: 101). En tercer término, señala la búsqueda de reconocimiento de fuentes hispánicas para cubanismos que

Cincuenta lecciones de exilio y desexilio (2000), escrito directamente en español, y Tongue Ties (2003). Joy Landeira distingue, a su vez, entre ensayos que siguen cierta tradición hispánica y otros, más nuevos, donde Pérez Firmat indaga las posibilidad de construir una subjetividad liminar (2012: 554). En parte de este mismo corpus, Guadalupe Silva analiza también la figura del exilio (2009).

21 “Aunque [Fernando Ortiz] no escribió novelas ni poemas, Pérez Firmat lo considera el escritor criollista más importante de Cuba por sus ensayos (1999: 29). [...] En My Own Private Cuba no se limita a un ensayo sobre Ortiz, sino que se explaya con cinco: 'The Cuban Condition', 'Mr. Cuba', 'The Politics of Enchantment', 'Cuban Counterpoint' y 'The Philological Fictions of Fernando Ortiz'” (Landeira 2012: 559-560).

${ }^{22} \mathrm{La}$ exitosa recepción de esta propuesta etimológica, está analizada en Salto (2010: 139-144). 
Ortiz consideraba mal atribuidos: "calimba", "fajatina" o "moringa" tendrían, en realidad, un origen peninsular. De este modo, Ortiz habría operado en tres claves glotopolíticas que ubicarían su obra en el límite, en el umbral de lo decible, en el limen entre filología y literatura: búsqueda de autonomía de las variedades locales frente a las hispánicas, reconocimiento de las influencias recíprocas y lucha por la legitimación entre unas y otras. Esa confluencia de estrategias disruptivas e irreverentes habría hecho posible que un tratado lexicográfico pudiera ser leído, a fines del siglo XX, como una "ficción filológica": "The Catauro is a philological fiction with a political theme" (Pérez Firmat 1985: 100).

La informalidad festiva y despectiva que, en 1923, en plena posguerra, ofrecía un espacio para la innovación y la autonomía léxica, varias décadas más tarde, aporta elementos para la construcción de una tradición filológica diferente, que redescubre el potencial político y glotopolítico del antiguo repertorio, del "diccionario del diablo". Su importancia actual no reside tanto en sus contribuciones a la lingüística histórica, como en la trama ficcional en la que engarza sus etimologías. Esa trama es ficcional porque no responde a descripciones de la lexicografía de la época, sino a hipótesis africanistas o indigenistas de dudosa autenticidad, que tienen como objetivo principal impugnar la ortodoxia hispana y monolingüe de los diccionarios de la época y ofrecer un dominio prospectivo para otro tipo de estudios léxicos. Estos nuevos estudios dan cabida a las lenguas de los otros y, sobre todo, a los usos lingüísticos de los desplazados del núcleo de la cubanía, ya sean los del "hampa cubana", que Ortiz estudió en los primeros años del siglo ${ }^{23}, \mathrm{o}$, décadas más tarde, los otros desplazados del territorio nacional. Por esta razón, el Catauro funciona como una "ficción filológica" con un objetivo político: actúa en el presente, pero es, sobre todo, un dispositivo a futuro.

$\mathrm{Su}$ tono festivo, su estructura deshilvanada y la inclusión abigarrada de materiales misceláneos lo acercan a los procedimientos vanguardistas -el pachtwork, el collage, la superposición de lo diverso y de lo distinto (Pérez Firmat 1986: 108). Sin embargo, aunque la estructura evoque los procedimientos vanguardistas, prima la noción de "catauro", un canasto que recolecta, mezcla, transporta y exhibe los materiales lingüísticos y étnicos. En una conferencia pronunciada en la Universidad de Florida sólo un año después, en 1987, Pérez Firmat distingue entre tres tipos de escritores, según sus respectivas posiciones sobre los usos lingüísticos:

${ }^{23}$ Ortiz dedicó varios estudios a esta categoría social. Se destaca la investigación inicial Hampa afrocubana: Los negros brujos (Apuntes para un estudio de etnología criminal), publicado en 1906 con prólogo de Cesare Lombroso. Para un estudio pormenorizado, véase Cass (2004). 
La literatura hecha por emigrados puede agruparse en literatura de inmigrantes (quienes se asimilan y escriben en la lengua de llegada), literatura del exilio (quienes se aferran al pasado y escriben en una lengua inexistente, incluso, en sus lugares de partida) y literatura "étnica" que se define por su otredad con respecto a ambos puntos, el de partida y el de llegada. [...] el escritor "étnico" no cultiva la identidad sino la diferencia. He ahí una de las razones que explican que la literatura étnica sea a menudo multilingüe. El escritor étnico - que no se siente comprometido ni con su lengua materna ni con la otra- utiliza lo que pudiéramos llamar el "lenguaje pertinente", o sea, la modalidad lingüística que mejor exprese su posición, equidistante de una y otra culturas (1987: n.p).

Ese "lenguaje pertinente", contrastante, contestatario y oposicionista -tal la definición de etnicidad que se sostiene en la entrevista - lo encuentra en el Catauro, en el "diccionario del diablo", donde las etimologías no responden a los estándares de la lexicografía académica, sino a las hipótesis disruptivas de una actividad filológica provocadora, que ofrece explicaciones etimológicas destinadas a intervenir en la batalla cultural más que a identificar o a consolidar variaciones léxicas. La obra lexicográfica de Fernando Ortiz llega a ser, así, el antecedente más notable de una "escritura étnica" moderna.

Una estrategia similar aparece en La isla que se repite (1989), publicada en Hanover por Antonio Benítez-Rojo (1931-2005) una década después. Este libro, que tanta repercusión alcanzó en la crítica, se inicia también con una dedicatoria al antropológoco, "maestro a distancia", que engarza el estudio sobre la cultura caribeña en una genealogía alternativa a la que caracteriza el discurso dominante (Díaz Quiñones 2007). La resignificación de las hipótesis africanistas de Ortiz contribuye a explicar, en este ensayo, la preeminencia posmoderna de lo caribeño, del archipiélago afro, en detrimento de la idea de una nación unicultural ${ }^{24}$. En otro episodio que puede parecer aislado, pero que forma la trama de lecturas donde se actualiza y resignifica el legado de Ortiz, Roberto González Echevarría (1943-) publica, en 2001, la versión en español de su libro The Voice of the Masters, que había aparecido en inglés en 1995. En esta segunda versión ampliada, La voz de los maestros. Escritura y autoridad en la literatura latinoamericana moderna, incluye el capítulo sobre "El Contrapunteo y la literatura", donde resalta, en una línea

24 Pocos años después, los jóvenes editores del Instituto Superior de Arte de Cuba rescataron del archivo de Fernando Ortiz más de cuarenta páginas de apuntes inconclusos, donde las etimologías africanistas del Catauro resuenan una y otra vez, y las publicaron, en 1992, en el número veinte de Albur, una revista cultural que oxigenaba un poco el ambiente de La Habana en los años del Período Especial. Cfr. la selección compilada por Diana María Ivizate González e Iván González Cruz. Albur. Revista Cultura Cubana (Órbita). Valencia: Generalitat Valenciana, 2002. 
similar a la de Gustavo Pérez Firmat la coincidencia temporal entre los juegos de palabras registrados en el Catauro y los localismos irlandeses del Ulysses de Joyce:

Pensemos también que el Catauro es casi estrictamente contemporáneo del Ulises de Joyce, que es de 1922, donde cunden los localismos irlandeses y juegos de palabras. Un estudio de esos trabajos de Ortiz que los cotejara punto por punto con los inicios de la vanguardia, y sobre todo del afrocubanismo, revelará cómo el autor de Los negros brujos se fue impregnando del espíritu de ésta [...] (González Echevarría 2001: 65) ${ }^{25}$.

En este caso, el crítico explica esta coincidencia por el interés de Fernando Ortiz en la literatura y, en especial, en sus prácticas más vanguardistas: "Para el que se imagine a Ortiz como científico social, resultará sorpresivo encontrar en sus libros, aún en los más técnicos acerca del baile o la música afrocubanos, alusiones certeras y oportunas a James Joyce" (2001: 62). Sin embargo, los juegos sonoros, los trabalenguas y experimentos verbales de Mariano Brull y otros miembros del Grupo Minorista o de la Revista de avance habrían establecido una interlocución no siempre reconocida con sus "cubicherías" léxicas. Por esta razón, pese a los afanes por fijar un único y ordenado sentido, el antiguo diccionario resiste el encasillamiento y ofrece, en cambio, un archivo que opera, desde el pasado, sobre las disrupciones del relato actual, sobre las diferencias étnicas, las migraciones, sus diásporas y exilios, sobre los bordes, o, para decirlo con los juegos de palabras de Ortiz, sobre las "cubicherías".

\section{Giros filológicos}

Los antiguos tratados de lexicografía deparan sorpresas. Su auge formó parte, entre fines del siglo XIX e inicios del XX, de los dispositivos culturales que intervinieron en la formación de los imaginarios nacionales y en la consecuente estandarización de la variedad de usos, registros y lenguas que convivían en el continente. Su productividad actual no se ciñe solo a la lingüística, sino que avanza sobre un dominio mucho más amplio del campo cultural, ya que ofrece la posibilidad de sortear los significados estatuidos y abrir el espectro hacia campos semánticos e ideológicos obturados durante años. Werner Hamacher señala, a propósito del renovado valor de la filología, que: "no se repite lo pasado, sino lo que de él va al futuro. La filología repite este proceso y busca del futuro lo que le falta del pasado" (2011: 29). En ese punto intermedio, es donde opera todavía el "diccionario del diablo" de Fernando Ortiz: entre los elementos léxicos del pasado

25 Una página después, González Echevarría llega a postular que el Contrapunteo cubano del tabaco y del azúcar (1940): "es un largo, prolijo, joyceano juego de palabras y conceptos, como los de un texto estrictamente contemporáneo suyo, Finnegans Wake" (2001: 66). 
que fueron al futuro, que no se anquilosaron en la historiografía lingüística porque fueron concebidos con la astucia de una ficción filológica, y las etimologías que los migrantes de hoy bucean ante el extrañamiento de una lengua que ya ha dejado de ser la propia. En este cruce, el Catauro de cubanismos ofrece algunas respuestas: del pasado ofrece al futuro sus heterogéneas "cubicherías" y, desde el futuro, aporta algo de lo que le falta al pasado, en su ironía, su distanciamiento, su inversión de los protocolos académicos. Este es, en gran medida, su enclave en la modernidad ${ }^{26}$ y lo ubica en el lábil, pero proteico concepto de liminalidad.

\section{BIBLIOGRAFÍA}

BENÍTEZ RoJo, Antonio.

1989 La isla que se repite. El Caribe y la perspectiva posmoderna. Hanover: Ediciones del Norte.

BIRKENMAIER, Anke.

2012 "Entre filología y antropología: Fernando Ortiz y el día de la raza". Antípoda, $\mathrm{n}^{\circ}$ 15, julio-diciembre, pp. 193-218.

CAMACHO BArreiro, Aurora.

2000 "Fernando Ortiz, lexicógrafo", Montalbán, no 33, pp. 269-279.

2000-2004 "Huellas ideológicas en la lexicografía cubana", Revista de lexicografia, $\mathrm{n}^{\mathrm{o}}$ 10, 2000-2004, pp. 21-38.

CASS, Jeremy Leeds.

2004 Fashioning Afrocuba: Fernando Ortiz and the Advent of Afrocuban Studies (906-1957). PhD Dissertation. Lexington: University of Kentucky.

CATAURO: UNA REVISTA CUBANA DE ANTROPOLOGÍA, año I, $\mathrm{n}^{\circ}$ 0, julio-diciembre de 1999.

CÓRDOBA RODRÍGUEZ, Félix.

1999 "En torno a los diccionarios de americanismos", Acta Universitatis Palackianae Olomucensis. Philologica, no 74, pp. 49-54.

DÍAZ QUIÑONES, Arcadio.

2007 "Caribe y exilio en La isla que se repite de Antonio Benítez Rojo", Orbis Tertius, año 12, n ${ }^{\circ}$ 13, pp.1-17.

FAY, Stephen.

2010 "Mapping the Cuban condition in Fernando Ortiz's Un catauro de cubanismos", New West Indies Guide / Nieuwe West-Indische Gids, vol. $84, \mathrm{n}^{\circ} 1$ \& 2, 2010, pp. 41-61.

${ }^{26}$ Cfr. "Un cautauro de cubanismos is The Waste Land of Modern dictionaries" (Pérez Firmat 1985: 108). 
FONT, Mauricio y Alfonso QUIROZ (eds.).

2005 Cuban Counterpoints: The Legacy of Fernando Ortiz. Lanham: Lexington Books.

GONZÁLEZ, Reynaldo.

2002 "Catauro de cubanismos", La ventana. En línea. Consultado el 3 de abril de 2015.

GONZÁLEZ ECHEVARRÍA, Roberto.

2001 "El Contrapunteo y la literatura", en La voz de los maestros. Escritura y autoridad en la literatura latinoamericana moderna. Madrid: Verbum, pp. 62-70.

GUITARTE, Guillermo L.

1991 "Del español de España al español de veinte naciones: la integración de América al concepto de lengua española", en Hernández, C. et al. El español de América. Actas del III Congreso Internacional de El Español de América. Valladolid: Junta de Castilla y León, pp. 65-86.

HAMACHER, Werner.

201195 tesis sobre la Filología. Buenos Aires: Miño y Dávila.

LANDEIRA, Joy.

2012 "Continuidades y diferencias ensayísticas en My Own Private Cuba: Essays on Cuban Literature and Culture de Gustavo Pérez Firmat", Revista Iberoamericana, vol. LXXVIII, $\mathrm{n}^{\circ}$ 240, julioseptiembre, pp. 555-566.

MAILHE, Alejandra.

2011 "Avatares de la conceptualización de la cultura negra en la obra de Fernando Ortiz, 1900-1940”. Orbis Tertius, año XVI, n 17, pp. 115.

MARINELLO VIDAURRETA, Juan.

1999 [1926-1928] "Un guacalito de cubanismos", Oralidad, no 10, pp. 4-18.

MARTÍNEZ, Marta.

1967 "Sobre el nuevo catauro de cubanismos". Universidad de La Habana, $\mathrm{n}^{\circ}$ 184-185, marzo-junio, pp. 171-175.

Motola Pedroso, Patricia.

2014 "Apuntes para la historia de la Academia Cubana de la Lengua", La Habana: Academia Cubana de la Lengua. En línea: http://www.acul.ohc.cu/historia.html

NARANJO OROVIO, Consuelo.

2003 "Creando imágenes, fabricando historia: Cuba en los inicios del siglo XX”, Historia mexicana, vol. 53, n 2, pp. 511-540.

ORTIZ, Fernando.

1923 Catauro de cubanismos. Apuntes lexicográficos. La Habana: s/e. 
1964 "Cubanidad y cubanía", Islas, vol. VI, n 2, pp. 91-96.

2014 Correspondencia de Fernando Ortiz, 1920-1929. Compilación y notas de Trinidad Pérez Valdés. La Habana: Fundación Fernando Ortiz.

ORTIZ GARCÍA, Carmen.

2003 "Cultura popular y construcción nacional: la institucionalización de los estudios de folklore en Cuba", Revista de Indias, vol. LXIII, $\mathrm{n}^{\circ}$ 229, pp. 695-736.

PALMIÉ, Stephan.

2010 "Fernando Ortiz y la cocción de la historia", Istor, $\mathrm{n}^{\circ}$ 40, pp. 31-54.

PÉREZ FIRMAT, Gustavo.

1986 Literature and Liminality. Festive Readings in the Hispanic Tradition. Durham: Duke University Press.

1989 The Cuban Condition: Translation and Identity in Modern Cuban Literature. Cambridge: Cambridge University Press.

1999 My Own Private Cuba: Essays on Cuban Literature and Culture. Boulder: Society of Spanish and Spanish-American Studies.

2013 [1987] "Trascender el exilio, la literatura cubano-americana hoy", La Jiribilla, vol. XI, $\mathrm{n}^{\circ}$ 614, febrero. En línea.

SALTO, Graciela.

2010 "La 'suave risa' cubana en la crítica cultural: del choteo al camp", en Graciela Salto (comp.). Memorias del silencio: literaturas en el Caribe y Centroamérica. Buenos Aires: Corregidor, pp. 123-150.

SILVA, Guadalupe.

2009 "Exilio y escritura en Gustavo Pérez Firmat", Confluenze, vol. 1, n 2, pp. 32-41.

SKLODOWSKA, Elzbieta.

2010 "Sin embargo: la literatura cubana y su crítica en la era de la globalización", Romance Notes, vol. 50, n 1, pp. 105-116.

SUÁREZ, Constantino [ESPAÑOLITO].

1921 Vocabulario cubano. Suplemento a la $14^{a}$ edición del Diccionario de la R. A. de la Lengua. La Habana, Librería Cervantes de Ricardo Veloso.

UNRUH, Vicky.

1994 Latin American Vanguards: The Art of Contentious Encounters. Berkeley: California University Press.

VALDÉS BERNAL, Sergio.

2006 "Un catauro de elogio y contrapunteo sobre los trabajos lingüísticos de Fernando Ortiz y Lydia Cabrera", Catauro, año 7, n 13 , enerojunio de 2006, pp. 67-77. 